\title{
A methodology for the sustainability assessment of agri-food systems: an application to the Slow Food Presidia project.
}

\author{
Cristiana Peano $^{1}, \underline{\text { Paola Migliorini }}^{2}$ and Francesco Sottile $^{3}$
}

\begin{abstract}
New and alternative models for agri-food production and consumption have brought up questions regarding the effects they have on local development processes in terms of the economic exploitation of rural areas as well as environmental, cultural, and social factors. The agri-food system proposed by the Slow Food (SF) Presidia Project, which focuses on farm-to-market systems for local, high-quality, sustainable products, can respond to the new and emerging needs of both rural and urban populaces via several approaches in addition to food production itself. However, evaluating these parameters is challenging. The aim of this study was to develop an indicator-based tool to monitor the sustainability in agri-food systems that considers quality as well as economic, ecological, social, and cultural aspects. We: (i) translated the major SF principles of "good," "clean," and "fair" into five major criteria to evaluate sustainability; (ii) designed multiple indicators to monitor progress toward sustainability for each of those criteria; and (iii) applied the monitoring tools to three case studies as a first attempt at end-use validation. Indicators and criteria were weighted either equally or based on their importance to surveyed stakeholders, i.e., consumers, producers, and scientists/experts. The proposed approach performed well as a tool for a broad sustainability evaluation by effectively combining the indicators with the same feedback. With this approach, we demonstrated that the SF Presidia project increases all dimensions of sustainability and in particular socioeconomic and cultural capital by preserving the environmental and quality aspects of the food products.
\end{abstract}

Key Words: agricultural and food systems; indicators; Slow Food; sustainability evaluation

\section{INTRODUCTION}

The World Commission on Environment and Development (1987) declared that sustainability means respecting the needs of the present generation without compromising the opportunity of future ones to meet their own needs. In 1992, the Convention for Biological Diversity (United Nations General Assembly 1992) defined the role of each international community to develop pathways to the real preservation of biodiversity. Wilson (1992) declared that the best way to preserve biodiversity is by giving it real economic value; this theorem is particularly relevant to agrobiodiversity. Consequently, in recent decades, the conscious consumer has started to develop a new approach to food consumption by considering quality, tradition, and local sources. The European Union has also developed systems to valorize highquality food through specific labels that are currently widely used in all member countries and testify to strong relationships between crops, food, local traditions, and cultures.

Over the past 50 years, agriculture has undergone considerable changes that have been strongly influenced by the specialization and standardization of production as well as by technology and wage relations (Hardt and Negri 2002). These factors have become essential components of the agricultural industry. Consequently, monocultures prevailed and, in particular, the natural environment has been drastically altered. We cannot neglect the positive effects of exogenous agricultural development, such as increased yields and commercially available commodities. At the same time, however, the many adverse effects of agricultural modernization are readily apparent: increased and widespread pollution, the rapid decay of agro-biodiversity, and the loss of traditional farming practices, cultures, and historical local knowledge.

Endogenous rural development utilizes and perpetuates local techniques, experience, and knowledge to convert local resources into quality products (van der Ploeg 1995). In this way, quality products depend upon the characteristics of the natural and human resources of an area and differ from other commodities because of their stronger connection with the local resources (Romano 1996, Brunori 2007). However, endogenous development is not based exclusively on local parameters; exogenous introductions are managed according to the "local style company" (e.g., a SF Presidium) to ensure maximum compatibility with the local conditions, prospects, and interests (van der Ploeg 1995).

Slow Food (SF) is an international movement founded in Italy and operating in many countries, on all continents. It started in 1989 by launching a campaign that focuses on "Good, Clean, and Fair" food (Petrini 2005:91). One of SF's operative tools is the Slow Food Foundation for Biodiversity whose primary goal is the preservation of old traditions linked to food, with the specific aim of preserving the diversity of locally grown crops and traditional crop management systems. Over the years, the foundation has developed several projects; one of these is the Slow Food Presidia project, which started in 1998. The holistic vision that characterizes the SF approach is not limited to the environmental, social, and economic aspects of sustainable development; rather, while taking them into account, it tries to define a more complex pathway to preserve the existing breadth of knowledge for future generations (Shiva 1993, 2009).

The development of a conscious relationship between food and its sustainable production (Goodman 2003) has been the basis for assessing the SF Presidia project. Each local presidium is related to a specific product, e.g., a vegetable, fruit tree, animal breed, cheese, or other high-quality processed product, and is strongly linked to tradition, region, culture, and agricultural history. Agrobiodiversity preservation is a focal point of all of the project's actions but does not solely define the goal of the project. Its

${ }^{1}$ Dipartimento di Scienze Agrarie, Forestali e Alimentari (DISAFA), University of Turin, Italy, ${ }^{2}$ University of Gastronomic Sciences, Pollenzo, Italy, ${ }^{3}$ Dipartimento di Scienze Agrarie e Forestali, University of Palermo, Italy 
approach and participatory way of implementing actions are also considered important. According to the Slow Food Foundation (2010), biodiversity is preserved by establishing a democratic system involving farmers, consumers, traders, chefs, local restaurants, and others. The agro-ecological approach to cultivation techniques is considered as the basis of a presidium, and all farmers are expected to follow specific production protocols. The democratic participation of all producers in the life and development of the presidium is particularly important to its success.

The Slow Food Foundation (2010) evaluates candidate products for a presidium considering specific criteria. First, the product must be good, in terms of taste and recognisability, and it must have a specific history in the region and be part of a traditional culture. It must be at risk of disappearing, so that its preservation maintains agro-biodiversity, and enhance environmental sustainability by developing an agro-ecological mode of production. Finally, the presidium must exemplify social and economic sustainability by using a democratic approach that considers farmer involvement and a small-scale dimension of farms.

In the SF approach, a presidium defines a new relationship between producers and consumers through the concept of "narrated quality." This concept considers that quality can be developed and made evident from many points of view; in the SF viewpoint, narration plays a fundamental role that can also overlap the analytical aspects of quality. Each product, group of producers, and traditional production system has a specific story that must be conveyed by the farmers to the consumers to let them appreciate the real life of the product and of the producers themselves, in other words, to form sustainable agri-food systems (SAFS).

No single definition of SAFS exists in the scientific literature nor is there a consensus on which criteria should be used to judge whether a food system is sustainable. A SAFS "provides healthy food to meet current food needs while maintaining healthy ecosystems that can also provide food for generations to come with minimal negative impact on the environment. A sustainable food system also encourages local production and distribution infrastructures and makes nutritious food available, accessible, and affordable to all. Further, it is humane and just, protecting farmers and other workers, consumers, and communities" (APHA 2007:1).

Generally, a SAFS must produce a quality product and be economically viable, ecologically feasible, socially just, and culturally acceptable. Evaluating such a system requires that the goals of the SAFS be clear, the stakeholders identified, and objective criteria to measure the goals be established, scored, and weighted (Christensen et al. 2012).

In this paper we aim to develop a multicriteria methodology inspired by the SF approach and assess whether the SF presidium project has managed to create a sustainable agri-food system (Peano et al., in press). Specifically, we tried to construct and use the multicriteria methodology as a communication and processfacilitating tool, sensitive to the SF's approach to sustainable agriculture food systems, including its emphasis on local aspects.
We also tested this multicriteria methodology by evaluating how it works as well as its effects and value for the development of a SF SAFS. We conclude with a discussion of the potentials and challenges of the method assessed. In this way, we address the mutual effects between the SF presidia and the assessment of the methodology.

\section{MATERIAL AND METHODS}

Our methodological steps were: (i) to create a new fivedimensional framework (quality, economic, social, environmental, and cultural dimensions) that translates the major SF principles of good, clean, and fair and the SF Presidia criteria into pragmatic and relevant themes for sustainability issues; (ii) to design indicators to monitor progress toward sustainability for each of those themes; and (iii) to apply our monitoring tool to three SF Presidia as a first attempt at end-use validation. Evaluation methods typically range from expert-based to farmer-based (Triste et al. 2014); in this case, farmers, consumers, and experts were all consulted regarding each of these methodological steps.

\section{The five-dimensional framework}

The evaluation of SAFSs elaborates issues of: impact assessment (CEC 2005); sustainable farming systems, land, landscape, and natural resource management (López-Ridaura et al. 2002, Van der Werf and Petit 2002, Pacini et al. 2009); local food systems (Schönhart et al. 2009); organic agriculture principles (IFOAM 2005); food policy and culture (Lang at al. 2009); diversified farming systems (Kremen et al. 2012). Similar parameters were considered by Lillywhite et al. (2012) in evaluating farming systems in the United Kingdom. In this paper, a new fivedimensional framework is provided to assess sustainability (Migliorini 2013) and we relate it to SF principles and Presidia criteria (Table 1).

\section{Designing indicators: criteria and validation}

We present a methodology with indicators to assess the quality and sustainability of the presidia. Many different indicators of sustainability have been published (Meadows 1998, Belle and Morse 1999, Flanders 1999, OECD 1999, 2001, CEC 2005). According to Segnestam et al. (2000), indicators are "pieces of information" that summarize the characteristics of systems or highlight what is happening in a system. The proposed methodology aims to simplify the complex phenomena and to measure the state of a system.

We selected a list of indicators for each of the five dimensions referring, in some cases, to existing methodologies and indicators, especially for the environmental and economic aspects, and in other cases, to new dimensions (quality and cultural). When solid and scientific information was not available, e.g., for the social and cultural aspects, we consulted stakeholders, i.e., experts and producers involved in the presidium project, to select and design relevant indicators. This approach was previously used by van Calker et al. (2005) and Meul et al. (2008). The list of indicators, in total 41 , is a new approach combining quality (5 indicators) and sustainability issues ( 5 cultural, 12 social, 15 environmental, 4 economic indicators). The score of the indicators is of two types: (a) quantitative, when a numeric range with specific unit of measurement can be obtained from the interviews; (b) qualitative (presence or absence or different type), when the indicator does 
Table 1. List of quality, environmental, social, economic, and cultural impact issues used previously to assess the sustainability of agrofood systems, with reference to the Slow Food criteria of good, clean, and fair.

\begin{tabular}{|c|c|c|c|}
\hline $\begin{array}{l}\text { Sustainability } \\
\text { Dimension } \\
\end{array}$ & Issue & SF Presidia Criteria & $\begin{array}{l}\text { Slow Food } \\
\text { Dimension } \\
\end{array}$ \\
\hline Quality & Freshness; local; seasonal; health, safety and security; nutrition; taste & Good & Good \\
\hline Environment & $\begin{array}{l}\text { Soil quality and resources; water quality and resources; air quality, air pollution } \\
\text { reduction; biodiversity enhancement (gene, species, and ecosystem levels); } \\
\text { landscape conservation; climate change mitigation; land use; renewable or } \\
\text { nonrenewable resources; waste production/generation/recycling; energy } \\
\text { consumption and efficiency; plant health and animal welfare }\end{array}$ & $\begin{array}{l}\text { Environmental and } \\
\text { risk of disappearing }\end{array}$ & Clean \\
\hline Economic & $\begin{array}{l}\text { Cost and access to food; consumers and household; income of farmers and food } \\
\text { manufacturers; trade and markets; operating and administrative costs of } \\
\text { business; regional added value; innovation and research; macroeconomic } \\
\text { environment }\end{array}$ & Small scale & Fair \\
\hline Social & $\begin{array}{l}\text { Employment and labor markets; standards and rights related to job quality and } \\
\text { work conditions; social inclusion and protection of particular groups; increasing } \\
\text { community power and personal relationships; social roles of producers and } \\
\text { reinforcing their willingness to organize themselves; communication network; } \\
\text { equity and nondiscrimination; access to education, health, justice, media; } \\
\text { landscape identity; security; governance and participation }\end{array}$ & Social & \\
\hline Cultural & $\begin{array}{l}\text { Cultural heritage; material and immaterial knowledge; ethnodiversity; } \\
\text { conserving traditional production techniques; embeddedness; cultural and } \\
\text { territorial identity; tourism; historical buildings }\end{array}$ & $\begin{array}{l}\text { History, part of } \\
\text { traditional culture }\end{array}$ & \\
\hline
\end{tabular}

not require a specific number. For each indicator used (Table 2), we defined minimum (0), intermediate (5), and maximum (10) qualitative value, enabling us to standardize each evaluation. When an indicator only evaluated a presence or an absence (yes or no), only minimum (0) and maximum (10) values were used in its scoring. Table 2 describes all of the indicators and their contribution to developing the methodological frame, as well as their impact on the weight of each indicator.

\section{Indicator weights}

To aggregate all indicators across the five dimensions, individual indicators must be weighted. Weighting depends on several factors, including subjective ones. Therefore, we approached weighting in two ways: (i) We assumed that all five dimensions were equally important and assigned a weight to each indicator based on the number of indicators within that dimension. For example, the five level-3 quality criteria were each weighted by one-fifth of the total for that dimension. (ii) We assumed that different stakeholders in the presidium project (producers, scientists/experts, and consumers) viewed the five dimensions differently, so we had each stakeholder category $(n=10$ per subgroup) prioritize each dimension and indicator using a questionnaire. Tables 3 and 4 report the weights given by each group of stakeholders to the five dimensions of the level 2 and level 3 indicators, respectively.

In both methodologies, the total weight of all five dimensions (level 1) equaled $100 \%$ to allow the two approaches to be compared. The potential extremes were 0 (all indicators in the five dimensions at the minimum score of zero) and +50 (all indicators in the five dimensions at the maximum score of ten).

\section{Application of the monitoring tool}

This methodology was applied to three SF Presidia case studies at two times: (a) before the establishment of the SF presidium (before 2002 when the producers were Presidium candidates); (b) after the establishment of the SF presidium (after 8 years of project management). The first assessment (before) was done analyzing written documents of the Presidium project candidate through data acquired from the Presidia association's producers; the second assessment (after) was based on semistructural interviews with the producers $30 \%$ of Presidia association producers). The assessment of the conditions before and after was then compared.

\section{Case studies}

The proposed methodology has been applied as a monitoring tool to some case studies to approach a first attempt of active validation. The methodological framework can obviously be applied to many agricultural systems; however, the approach developed through the selected indicators, in this case, certainly appears specific to small and local agro-food systems. The study described here was applied to three Slow Food Presidia that have been set up in different regions:

Caper of Salina (Sicily, Italy)

The Capparis spinosa $\mathrm{L}$. is a perennial shrub that is mostly spontaneous and cultivated in the Aeolian archipelago. The strong competition from lower-quality and cheaper capers from Middle Eastern and North African countries and the necessarily manual nature of cultivation have been the main causes of the decline in the growing area and production of the products as well as its high risk of disappearing, which determined the reason the Presidium was established in 2002.

Lentil of Santo Stefano di Sessanio (Abruzzo, Italy)

The Lens culinaris Medik. cultivated in central Italy where the long and severe winters are ideal for the lentils but the hilly and mountainous landscape makes mechanization impossible. Thus the lentil cultivation is managed in a traditional way. Using the presidium approach, since 2004, all of the producers are part of an association to commercialize the product with a unique label. 
Table 2. List of indicators used to evaluate quality and environmental, social, economic, and cultural aspect of sustainability of Slow Food Presidia, with their dimension (level 1, 2, and 3), definition, unit of measurement (u.m.), scores, and value.

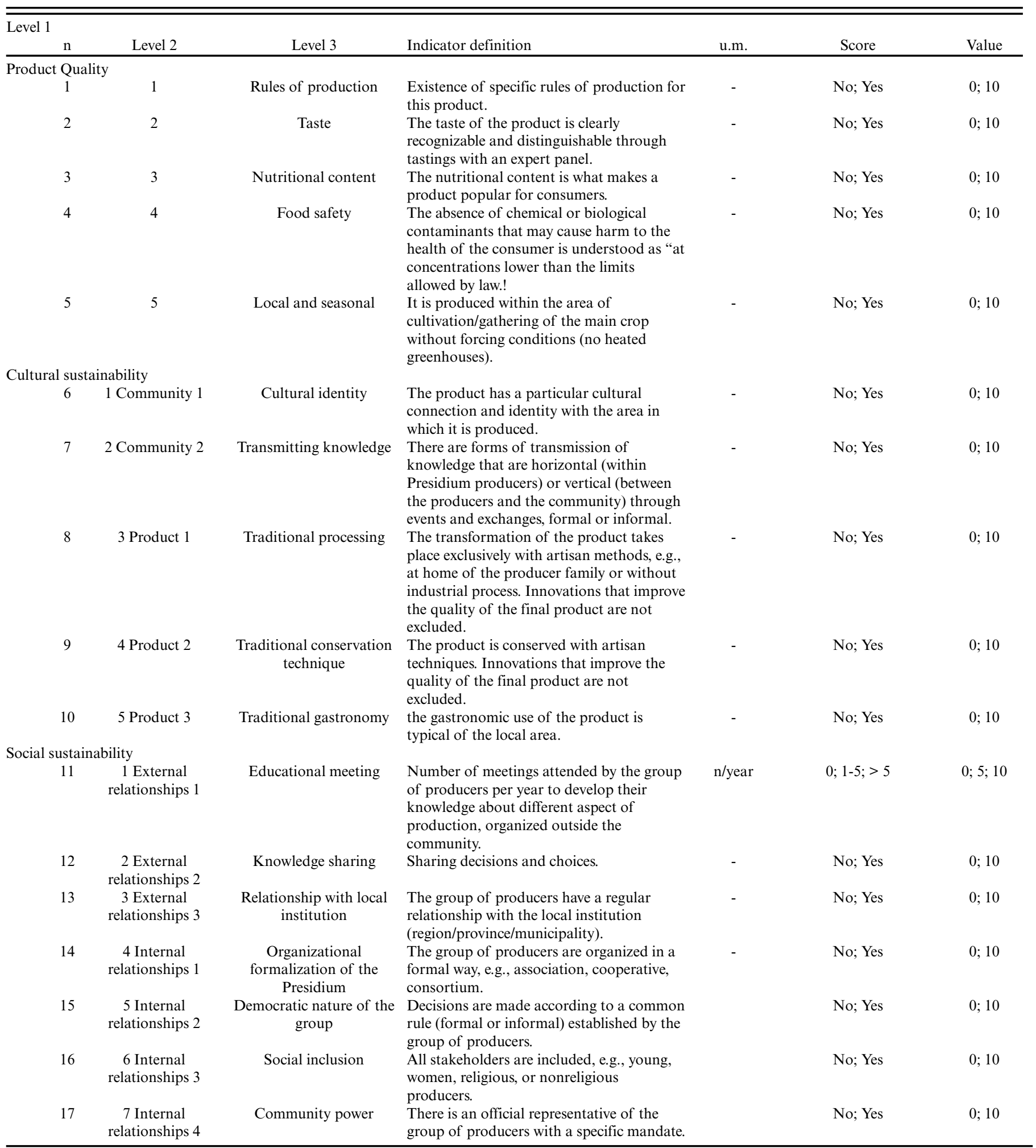




\begin{tabular}{|c|c|c|c|c|c|c|}
\hline 18 & $\begin{array}{l}8 \text { Internal } \\
\text { relationships } 5\end{array}$ & $\begin{array}{l}\text { Meeting between } \\
\text { producers }\end{array}$ & $\begin{array}{l}\text { Number of meetings attended by the group } \\
\text { of producers per year to exchange } \\
\text { information, organized by them. }\end{array}$ & $\mathrm{n} /$ year & $0 ; 1-10 ;>10$ & $0 ; 5 ; 10$ \\
\hline 19 & $\begin{array}{l}9 \text { Internal } \\
\text { relationships } 6\end{array}$ & $\begin{array}{l}\text { Meeting with } \mathrm{SF}^{\dagger} \text { head } \\
\text { office }\end{array}$ & $\begin{array}{l}\text { Number of meetings attended by the group } \\
\text { of producers per year with the SF head } \\
\text { office. }\end{array}$ & $\mathrm{n} /$ year & $0 ; 1-10 ;>10$ & $0 ; 5 ; 10$ \\
\hline 20 & $\begin{array}{l}10 \text { Internal } \\
\text { relationships } 7\end{array}$ & Educational activity & $\begin{array}{l}\text { Number of meetings organized by the } \\
\text { producers per year to explain the products, } \\
\text { e.g., taste event, attended by students, } \\
\text { consumers, tourists, institutional } \\
\text { representatives. }\end{array}$ & n/year & $0 ; 1-10 ;>10$ & $0 ; 5 ; 10$ \\
\hline 21 & 11 Social roles 1 & $\begin{array}{l}\text { Pride and social } \\
\text { gratification }\end{array}$ & $\begin{array}{l}\text { Producers are aware of their role, which is } \\
\text { recognized by the local community and } \\
\text { external stakeholders, e.g., universities, } \\
\text { institutions. }\end{array}$ & - & No; Yes & $0 ; 10$ \\
\hline 22 & 12 Social roles 2 & Producers number & $\begin{array}{l}\text { Increase in the number of producers over a } \\
\text { defined amount of time. }\end{array}$ & $\%$ & $0 ; 1-100 ;>100$ & $0 ; 5 ; 10$ \\
\hline 24 & 2 Biodiversity 2 & Species diversity 1 & $\begin{array}{l}\text { Number of species cultivated in the } \\
\text { producer farm. }\end{array}$ & $\mathrm{n}$ & $<6 ; 6-20 ;>20$ & $0 ; 5 ; 10$ \\
\hline 25 & 3 Biodiversity 3 & Species diversity 2 & $\begin{array}{l}\text { Number of autochthonous species } \\
\text { cultivated in the producer farm. }\end{array}$ & $\mathrm{n}$ & No; Yes & $0 ; 10$ \\
\hline 26 & 4 Biodiversity 4 & Genetic diversity & $\begin{array}{l}\text { Methods of reproduction of seed of the } \\
\text { main crop in the producer farm. }\end{array}$ & Type & $\begin{array}{l}\text { asexual; self- } \\
\text { reproducing; exchange }\end{array}$ & $10 ; 10 ; 10$ \\
\hline 27 & 5 Water and Air 1 & Water quantity 1 & $\begin{array}{l}\text { Amount of water used in the producer farm } \\
\text { that comes from alternative sources, e.g., } \\
\text { recycling, rainwater utilization. }\end{array}$ & $\%$ & $<30 ; 30-50 ;>50$ & $0 ; 5 ; 10$ \\
\hline 28 & 6 Water and Air 2 & Water quantity 2 & Type of irrigation used for the main crop. & - & $\begin{array}{l}\text { Flow; sprinkler; } \\
\text { localized; emergency; } \\
\text { rainfed }\end{array}$ & $0 ; 4 ; 6 ; 8 ; 10$ \\
\hline 29 & 7 Water and Air 3 & Water quality & $\begin{array}{l}\text { Amount of pesticide used (active } \\
\text { ingredient) in the producer farm. }\end{array}$ & $\mathrm{kg} \mathrm{a.i/ha}$ & $0 ; 0-10 ;>10$ & $0 ; 5 ; 10$ \\
\hline 34 & 12 Soil 3 & Crop rotation & Duration of the crop rotation. & year & $<2 ; 2-4 ;>4$ & $0 ; 5 ; 10$ \\
\hline 35 & $\begin{array}{c}13 \text { Energy and waste } \\
1\end{array}$ & Renewable source & $\begin{array}{l}\text { Eenewable energy sources utilized in the } \\
\text { farm. }\end{array}$ & $\%$ & $0 ; 0-50 ;>50$ & $0 ; 5 ; 10$ \\
\hline 36 & $\begin{array}{l}14 \text { Energy and waste } \\
2\end{array}$ & Packaging 1 & $\begin{array}{l}\text { Packaging reduction over a defined amount } \\
\text { of time. }\end{array}$ & $\%$ & $0 ; 0-20 ;>20$ & $0 ; 5 ; 10$ \\
\hline 37 & $\begin{array}{l}15 \text { Energy and waste } \\
\qquad 3\end{array}$ & Packaging 2 & $\begin{array}{l}\text { Type of the material used to pack the } \\
\text { product. }\end{array}$ & - & $\begin{array}{l}\text { recyclable; recyclable } \\
\text { and biodegradable; } \\
\text { recyclable, } \\
\text { biodegradable, and } \\
\text { compostable }\end{array}$ & $0 ; 5 ; 10$ \\
\hline \multicolumn{7}{|c|}{ Economic sustainability } \\
\hline 38 & 1 & Supply chain & $\begin{array}{l}\text { Amount of diversification of the supply } \\
\text { chain. }\end{array}$ & $\mathrm{n}$ & $\begin{array}{c}1 \text { typology; } 2 \text { typology; } \\
3 \text { typology }\end{array}$ & $0 ; 5 ; 10$ \\
\hline 39 & 2 & Price & $\begin{array}{l}\text { Deviation from the reference price of the } \\
\text { product. }\end{array}$ & $\%$ & $0 ; 0-50 ;>50$ & $0 ; 5 ; 10$ \\
\hline 40 & 3 & Aggregation & Forms of bundling to sell the products. & - & No; Yes & $0 ; 10$ \\
\hline 41 & 4 & Production area & $\begin{array}{l}\text { Increase of the production area in a defined } \\
\text { period. }\end{array}$ & $\%$ & $0 ; 1-50 ;>50$ & $0 ; 5 ; 10$ \\
\hline
\end{tabular}


Table 3. Weights assigned to each of five dimensions by the three presidia stakeholder categories.

\begin{tabular}{lcccc}
\hline \hline $\begin{array}{l}\text { Dimension } \\
\text { (Level 1) }\end{array}$ & $\begin{array}{c}\text { Equal weights } \\
(\%)\end{array}$ & $\begin{array}{c}\text { Consumers } \\
\text { Average (\%) } \pm \text { SD }\end{array}$ & $\begin{array}{c}\text { Scientists/Experts } \\
\text { Average (\%) } \pm \text { SD }\end{array}$ & $\begin{array}{c}\text { Presidia producers } \\
\text { Average (\%) } \pm \text { SD }\end{array}$ \\
\hline Quality & 20 & $44 \pm 14.30$ & $24 \pm 9.9$ & $26 \pm 9.40$ \\
Cultural sustainability & 20 & $13 \pm 4.22$ & $19 \pm 8.8$ & $11 \pm 7.18$ \\
Social sustainability & 20 & $17 \pm 5.33$ & $13 \pm 4.5$ & $18 \pm 8.94$ \\
Environmental sustainability & 20 & $13 \pm 3.89$ & $16 \pm 7.9$ & $22 \pm 7.68$ \\
Economic sustainability & 20 & $13 \pm 4.60$ & $28 \pm 15.4$ & 100 \\
& 100 & 100 & 100 & 100 \\
\hline
\end{tabular}

Wild Service Tree of Wiesenwienerwald (Austria)

The Sorbus torminalis (L.) Crantz is spread throughout the Schöpfl hill, near Vienna, Austria, where the tradition of eating its fruit (fresh or dried) and transforming it into distillates and other products is still evident. Very old trees produce delicious fruits that are harvested with difficulty in October by farmworkers who climb the tall trees. This Presidium was launched in 2008.

\section{RESULTS}

\section{Weights of indicators}

The weights assigned to each of the five dimensions of quality and sustainability by the stakeholders are presented in Table 3 . Consumers placed much more importance on quality than on sustainability. The scientists/experts valued economic sustainability and quality more than cultural, environmental, and social sustainability. Presidia producers emphasized social and cultural sustainability less. When the individual indicators of quality were considered (Table 4), consumers were clearly more interested in health, safety, security and taste while producers valued taste as well as the rules of production highly. Experts weighted the quality aspects almost equally, except that they felt that nutritional content was less important. Regarding cultural sustainability, experts and producers had similar views, while consumers paid more attention to traditional gastronomy than cultural identity. Regarding social sustainability, all stakeholders considered the social role of producers to be very important, together with environmental sustainability. For consumers, price was the most important aspect of economic sustainability, but diversification of the supply chain was also of concern to them. Price was also important for producers, while the other three aspects were almost equally important to them. The experts considered diversification of the supply chain most important, while price was least critical.

\section{Case study feedback}

Figure 1 summarizes the results of the equal-weights analysis of the five dimensions (level 1) for each of the three case studies (capers, lentils, and service trees) before and after the inauguration of the presidia. For each of the three case studies, participation in the SF Presidia project improved the total sustainability score; the average value before the inauguration of the presidia was 9.3, while afterward it was 30 . In addition, the scores of each of the five component dimensions of sustainability increased. Note that the value assigned for economic sustainability before each presidium was established was 0 , considered as a starting point of the process, to evaluate the economic progress. In each of the individual case studies after the establishment of the presidia, there was substantial variability in the weights assigned to each dimension by the different stakeholders.
Overall, the equal-weights approach yielded lower total sustainability scores, if compared with stakeholder evaluation. In any case, its values improved considerably after the presidia were established (Fig. 1). By using an alternative approach that weighted indicators according to their importance to different stakeholder categories, the increase in total sustainability was evident (i.e. in the case of capers the total score for consumers was 37, while that of the producers was 33) although the expert opinion evaluation gave similar results to that of the equal weights approach.

Fig. 1. Total sustainability scores estimated using the equalweights methodology. The contributions of each of the five dimensions to the total scores are indicated.

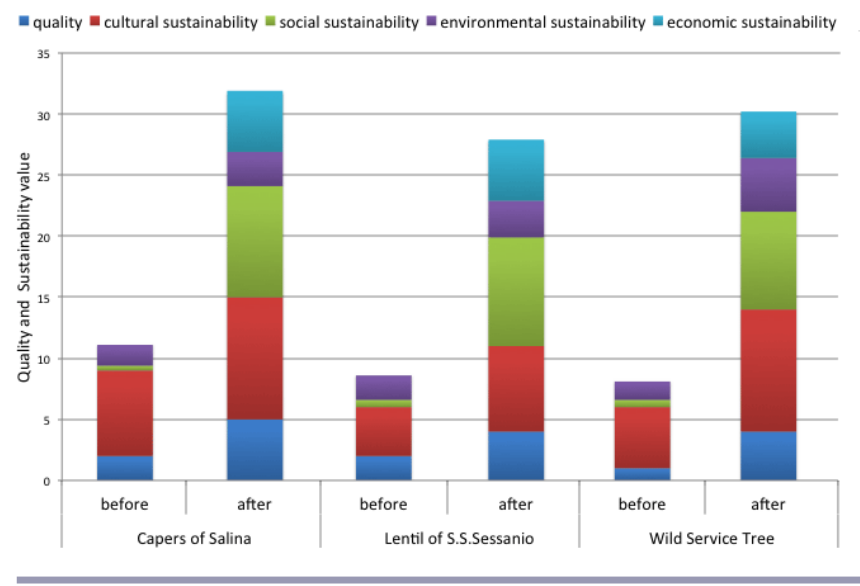

\section{EFFECTS OF THE APPLIED METHOD}

\section{Effects on food quality}

Many aspects of food quality can be analyzed, and taste is one of the most important. For presidia, the SF Foundation uses internal taste panels to evaluate quality while also involving experts from various fields. Presidia products are also all based on local food systems, because they are produced and consumed within a specific region, and they are seasonal and fresh. As already demonstrated by Freyer and Bingen (2012) for the organic food chain, the system related to the SF Presidium could be considered socially networked with a safer approach than heavily regulated ones. In this analysis, the differences in quality before and after the presidia were established, 1.7 and 4.3 respectively, could mainly be attributed to the application of production rules, which did not exist previously. 
Table 4. Weights (average and standard deviation) assigned to each of the indicators by different stakeholders within the five dimensions of quality, economic sustainability (both at level 3), and cultural, social, and environmental sustainability (at level 2).

\begin{tabular}{|c|c|c|c|c|c|}
\hline \multicolumn{2}{|c|}{ Dimensions } & \multirow{2}{*}{$\begin{array}{c}\begin{array}{c}\text { Equal } \\
\text { weights }\end{array} \\
\%\end{array}$} & \multicolumn{3}{|c|}{ Weights according to } \\
\hline Level 1 & Levels 2 and 3 & & $\begin{array}{c}\text { Consumers } \\
\text { Average (\%) } \\
\pm \text { SD } \\
\end{array}$ & $\begin{array}{c}\text { Scientists/Experts } \\
\text { Average }(\%) \\
\pm \text { SD } \\
\end{array}$ & $\begin{array}{c}\text { Presidia producers } \\
\text { Average }(\%) \\
\pm \text { SD } \\
\end{array}$ \\
\hline \multirow[t]{6}{*}{ Quality } & & 100 & 100 & 100 & 100 \\
\hline & Rules of Production & 20 & $6 \pm 5.16$ & $19 \pm 8.0$ & $28 \pm 13.61$ \\
\hline & Taste & 20 & $30 \pm 12.02$ & $23 \pm 8.6$ & $31 \pm 11.65$ \\
\hline & Nutritional content & 20 & $15 \pm 10.54$ & $13 \pm 8.4$ & $12 \pm 7.68$ \\
\hline & Health, safety, security & 20 & $33 \pm 10.33$ & $23 \pm 16.4$ & $13 \pm 9.23$ \\
\hline & Local and seasonal & 20 & $16 \pm 10.22$ & $22 \pm 14.7$ & $16 \pm 9.40$ \\
\hline \multicolumn{2}{|c|}{ Cultural sustainability } & 100 & 100 & 100 & 100 \\
\hline & Cultural identity & 20 & $10 \pm 9.43$ & $20 \pm 14.5$ & $17 \pm 10.31$ \\
\hline & Transmitting knowledge & 20 & $17 \pm 11.35$ & $24 \pm 11.0$ & $15 \pm 8.27$ \\
\hline & Traditional processing & 20 & $17 \pm 11.35$ & $19 \pm 7.9$ & $24 \pm 13.92$ \\
\hline & Traditional conservation technique & 20 & $27 \pm 13.98$ & $15 \pm 6.6$ & $21 \pm 3.08$ \\
\hline & Traditional gastronomy & 20 & $29 \pm 14.30$ & $19 \pm 10.0$ & $23 \pm 4.70$ \\
\hline \multicolumn{2}{|c|}{ Social sustainability } & 100 & 100 & 100 & 100 \\
\hline & External relationship & 33 & $23 \pm 13.98$ & $24 \pm 12.2$ & $33 \pm 14.55$ \\
\hline & Internal relationship & 33 & $21 \pm 11.74$ & $25 \pm 13.7$ & $31 \pm 13.34$ \\
\hline & Social role of producers & 33 & $56 \pm 25.47$ & $51 \pm 20.7$ & $36 \pm 9.40$ \\
\hline \multicolumn{2}{|c|}{ Environmental sustainability } & 100 & 100 & 100 & 100 \\
\hline & Biodiversity and landscape & 25 & $34 \pm 10.22$ & $38 \pm 16.0$ & $65 \pm 26.06$ \\
\hline & Air and water & 25 & $24 \pm 3.94$ & $19 \pm 7.1$ & $11 \pm 9.68$ \\
\hline & Soil & 25 & $20 \pm 5.77$ & $20 \pm 7.1$ & $16 \pm 12.31$ \\
\hline & Energy & 25 & $22 \pm 2.58$ & $24 \pm 8.6$ & $8 \pm 7.68$ \\
\hline \multicolumn{2}{|c|}{ Economic sustainability } & 100 & 100 & 100 & 100 \\
\hline & Supply chain diversification & 25 & $37 \pm 15.49$ & $31 \pm 23.4$ & $24 \pm 12.31$ \\
\hline & Price & 25 & $43 \pm 9.19$ & $19 \pm 7.4$ & $30 \pm 13.76$ \\
\hline & Forms of bundling & 25 & $9 \pm 12.65$ & $26 \pm 12.2$ & $23 \pm 13.02$ \\
\hline & Increase of production area & 25 & $11 \pm 11.74$ & $24 \pm 11.4$ & $23 \pm 10.31$ \\
\hline
\end{tabular}

\section{Effects on the cultural system}

The concept of localized food and product production is not only based on geographic region but also on cultural knowledge (Bérard and Marchenay 2004). In our three case studies, cultural sustainability increased (from 5.3 to 9.0 ) because of the actions of the producers together with local associations that promoted similar initiatives, such as publications about the area, activities related to local tourism and culture, and the renovation of historical buildings. Thus, the presidium project offered a starting point for other local, rural development projects. These findings were consistent with several comparable international studies that documented the key roles of local associations and social capital in promoting sustainable agriculture, with benefits ranging from higher yields to a wider adoption of agro-ecology practices, and achieving a broad set of social goals (Pretty and Ward 2001, Tregear 2001).

\section{Effects on the social system}

The social effect of a presidium was not easy to quantify for the Italian presidia. Social objectives can be considered a way to improve the social role of producers and reinforce their willingness to organize themselves.

In this analysis, we considered three categories of the social dimension (external relationship, internal relationship, social role of producers). Within each presidium, the producers increased their relationships with the "external world" and had opportunities to meet and share experiences among themselves and other presidia producers (from 0 to 9 for the caper, 1 to 9 for the lentils, and 1 to 8 for the wild services tree, before and after the presidia, respectively). The three Presidia develop and continue a "virtuous" trajectory thanks to a network of players (producers, refiners, salespeople, chefs, technicians, teachers, students, journalists, food lovers, food buying groups, etc.) that, in various ways, collaborate to safeguard, improve, and promote production all to raise awareness of products, producers, and regions, even in contexts that are far removed from the area where the actual production takes place. This aspect is possible thanks to the important role of the Slow Food association, which facilitates the networking of these various parties, the promotion of the products, as well as communication. Ultimately, the social changes that could enable presidia to scale up and out will be fashioned by the aspirations and actions of people (Kloppenburg et al. 2000, Bacon et al. 2012).

\section{Effects on the environment}

Environmental goals are vital for each presidium, because they are essential to the preservation of biodiversity and the improvement of sustainable food production. Each presidium production protocol requires the producers to avoid or reduce the use of chemical treatments, to consider animal welfare when adopting animal husbandry, and to protect local breeds and 
vegetable varieties whenever possible. The use of varieties and breeds adapted to local environments can reduce or eliminate the use of chemicals and excessive water consumption.

Our examination revealed encouraging results. The overall effects of the presidia on the environment were positive (1.7 and 3.4, before and after the presidia, respectively), although much remains to be done: the packaging of some products was neither minimal nor biodegradable, and very few producers have invested in clean energy. Our research suggested that many diversified farming systems can be designed that are equally productive and that maintain or enhance the ecosystem. In the case of the lentils of Santo Stefano di Sessanio, changes carried out to develop more sustainable practices at each stage of processing are important. A greater focus on natural methods of weed control and high sustainability postharvest treatments (cold treatments or natural drying) is particularly relevant. Other positive measures include the introduction of varietal fields for a shared reproduction of seeds as well as efforts to maintain purity by using individual packaging (in the past lentils were mainly sold in bulk).

\section{Economic effects}

The economic objectives can be measured by the producers' remuneration (increased prices and quantities), which leads to local economic growth and additional employment (more workers). Our study showed that the price of the final product increased, although not for the wild service tree. For the lentils of Santo Stefano di Sessanio, the price has increased from 6 to $15 € /$ $\mathrm{kg}$, for the capers of Salina from 4 to $11 € / \mathrm{kg}$. Market price is critical, because the goal of the presidium project is to find an optimal balance for both producers and consumers. The increased area of cultivation also indicated a direct positive effect on agrobiodiversity. As already mentioned before, for the lentils of Santo Stefano di Sessanio and the capers of Salina, the acreage has almost doubled. Moreover, the presidia established alliances among producers to gain more market power. In all three presidia, an association of producers was formed in compliance with Slow Food's rules and the producers sell their products together.

\section{Weighting schemes and reflection on tool}

We applied four different weighting schemes to our raw data: equal weights, and weights based on surveys of consumers, producers, and scientists/experts in the three presidia. Although the weighting schemes varied substantially, the presidia showed marked improvement in all measures of sustainability regardless of the weighting method. We used the same stakeholder-based weighting method for all presidia. Schader et al. (2014) argued that such a "one-size-fits-all" approach loses precision; although we generally agree with this statement, our "universal" metric for the three presidia gave similar indications of improvement as the equal-weights approach. This determines that the proposed method, independently of the weighing scheme used, appears to be considerably effective in providing information on the sustainability of a system.

With this evaluation system, we assessed the impact of SF presidia with a set of quality and sustainability indicators, providing a complete and relevant decision-making and communication tool. The methodological approaches to the assessment of sustainability in agriculture have several advantages, disadvantages, and limitations. A comparison between detailed and comprehensive frameworks for the evaluation of agricultural sustainability is provided by Van Cauwenbergh et al. (2007). They also showed that these frameworks mostly lack a holistic approach because they have a partial view of a sustainability scheme. Moreover, several approaches have been proposed by using indicators that involve experts for their quantification.

Even if these approaches are more accurate and sensitive, they usually need substantial financial support to be carried out. The proposed methodology, however, takes into account the ordinary three components of sustainability along with two additional ones (cultural and quality sustainability) that include indicators that are easily addressed through interviews to growers. Additionally, the contribution made by the growers themselves to monitor sustainability continues the participatory approach that contributes to the development of democracy inside the project and to the satisfaction of needs on a local basis (Reed et al. 2005).

With all of these aspects, the sustainability assessment has beneficial effects allowing the governance of the Presidium project to regularly monitor and effectively influence the path toward sustainability on both a single-case basis or on an entire-project basis. Also, this approach makes the results widely effective in small-scale systems that are structurally similar to those analyzed. Van Cauwenbergh et al. (2007) showed that the wide effectiveness of an approach is particularly useful and it depends on the holistic view of all of the aspects that are able to influence the development of sustainability.

As already reported by De Groot et al. (2002), the general framework applied in order to analyse sustainability is quite valid in similar-scaled systems although indicators have to be considered highly specific in relation to precise cases. The benefit that emerged from our methodology is a high integration determined by a multicriteria approach that allowed a thorough evaluation of the sustainability traits and their multidisciplinary behavior.

In any case, sufficient attention should be paid to the attitude of model users, compatibility, data availability and user-friendliness, particularly when a sustainable assessment model is used in existing networks. Some possible improvements in the sustainable assessment model and its use are: more focus on the organization of the discussion sessions, training of advisers and enhancement of their facilitation skills, involvement of experts and a thorough planning of sessions. All of these improvements could contribute towards making the model even more effective in supporting learning and sustainable farm management (De Mey et al. 2011).

\section{CONCLUSION}

It should be noted that the proposed approach allows a real integrated vision of sustainability in small-scale systems such as those developed under the SF Presidia project. The assessed methodology was seen to be well integrated with the SF approach and represented a valuable tool to measure the SF presidia as a SAFS. The careful selection of sustainability indicators is evident because of a series of reliable criteria that were obtained through simple and direct contact with growers in a participatory way. One of the most innovative features of this approach, however, is based on the multicriteria assessment with sustainability indicators; 
moreover, even if we varied the weight assigned to each indicator on the basis of the stakeholders, the method showed substantial vigour and minimized any possible errors that might arise in each indicator, thereby making the method easy to apply and appropriate for use.

Despite significant differences in agricultural practices, i.e., chemical vs. organic fertilizers, and marketing approaches, i.e., conventional market vs. alternative food networks, among the three case studies, this study showed that a SF SAFS derives dynamism from a regional sociocultural identity. The ex post assessment of food-system sustainability performed by the proposed methodology showed that the socioeconomic aspects exceeded expectations. In fact, as the analysis showed, the presidium projects provided a strategy for farmers to remain on the land and to regain some power and control over their productive relationships, and thus the social and cultural goals were reached. Moreover, in this model, the environmental objectives were attained by training farmers and field technicians; such training must continue to be an element of research, innovation, and development. Finally, cultural aspects were respected and enhanced. In this context, presidia products can reinforce rural agro-ecosystems, creating dynamics involving economic satisfaction, environmental concerns, and social and cultural background, through collective processes aimed at promoting the region as a whole.

Although it is evident however that the methodological proposal needs further research to be validated and improved, we do consider that our results provide some new insights, i.e., cultural aspects as well as quality of the product, to evaluate the sustainability of small-scale agri-food systems and to help growers to successfully increase the sustainability of their product. The weakest part of the proposed methodology still remains the small amount of quantitative indicators together with the need to validate it with a larger number of case studies. That is why we intend to carry out a wider application of this methodology to a consistent number of presidia, representative of different areas/ countries and product types.

Responses to this article can be read online at: http://www.ecologyandsociety.org/issues/responses. php/6972

\section{Acknowledgments:}

The authors wish to thank the two anonymous reviewers for their excellent comments and contributions in improving the initial version of the paper as well as all of the stakeholders involved on a voluntary basis in the assessment of the method. The authors are also grateful to Cassandra Funsten (BA at UC Berkley) for her fundamental assistance editing the English of the final version of the paper.

\section{LITERATURE CITED}

American Public Health Association (APHA). 2007. Toward a healthy sustainable food system. Policy Statement 200712. APHA, Washington, D.C., USA. [online] URL: http://www.apha.org/ policies-and-advocacy/public-health-policy-statements/policydatabase/2014/07/29/12/34/toward-a-healthy-sustainable-food-system

Bacon, C. M., C. Getz, S. Kraus, M. Montenegro, and K. Holland. 2012. The social dimensions of sustainability and change in diversified farming systems. Ecology and Society 17(4): 41 . http:// dx.doi.org/10.5751/ES-05226-170441

Bell, S., and S. Morse. 1999. Sustainability indicators: measuring the immeasurable? Earthscan, London, UK.

Bérard, L., and P. Marchenay, 2004. Les produits de terroir - Entre culture et règlements - CNRS Éditions, Paris, France.

Brunori, G. 2007. Local food and alternative food networks: a communication perspective. Anthropology of Food S2 March. [online] URL: http://aof.revues.org/index430.html

Christensen, T., S. B. Olsen, A. Dubgaard, and N. Kaergård. 2012. Organic farming and multi-criteria decisions: an economic survey. In Producing and reproducing farming systems: new models of organisation for sustainable food systems of tomorrow. 10th European IFSA symposium. International Farming Systems Association - Europe Group, Vienna, Austria. [online] URL: http://ifsa.boku.ac.at/cms/fileadmin/Proceeding2012/ IFSA2012 WS6.1 Christensen.pdf

Commission of the European Communities (CEC). 2005. Impact assessment guidelines. SEC(2005) 791. CEC, Brussels, Belgium.

De Groot, R. S., M. A. Wilson, and R. M. J. Boumans. 2002. A typology for the classification, description and valuation of ecosystem functions, goods and services. Ecological Economics 41:393-408. http://dx.doi.org/10.1016/S0921-8009(02)00089-7

De Mey, K., K. D’Haene, F. Marchand, M. Meul, and L. Lauwers 2011. Learning through stakeholder involvement in the implementation of MOTIFS: an integrated assessment model for sustainable farming in Flanders. International Journal of Agricultural Sustainability 9:350-363.

Flanders, L. 1999. Indicators of sustainable development (ISD), progress from theory to practice. Division for Sustainable Development, Department of Economic and Social Affairs, United Nations, New York, New York, USA.

Freyer, B., and J. Bingen 2012. Reflexivity or assessment? The role of self-reflexivity in the assessment process. In Producing and reproducing farming systems: new models of organisation for sustainable food systems of tomorrow. 10th European IFSA symposium. International Farming Systems Association - Europe Group, Vienna, Austria. [online] URL: http://ifsa.boku.ac.at/ cms/fileadmin/Proceeding2012/IFSA2012_WS6.1_Bingen_Freyer. pdf

Goodman, D. 2003. The quality 'turn' and alternative food practices: reflections and agenda. Journal of Rural Studies 19:1-7. http://dx.doi.org/10.1016/S0743-0167(02)00043-8

Hardt, M., and A. Negri 2002. Impero, il nuovo ordine della globalizzazione. Rizzoli, Milano, Italy.

International Federation of Organic Agricultural Movement (IFOAM). 2005. The principles of organic agriculture. IFOAM, Bonn, Germany. 
Kloppenburg, J., Jr., S. Lezberg, K. de Master, G. W. Stevenson, and J. Hendrickson. 2000. Tasting food, tasting sustainability: defining the attributes of an alternative food system with competent, ordinary people. Human Organization 59(2):177-186.

Kremen, C., A. Iles, and C. Bacon. 2012. Diversified farming systems: an agroecological, systems-based alternative to modern industrial agriculture. Ecology and Society 17(4): 44. http://dx. doi.org/10.5751/ES-05103-170444

Lang, T., D. Barling, and M. Caraher. 2009. Food policy: integrating health, environment and society. Oxford University Press, Oxford, UK. http://dx.doi.org/10.1093/acprof: oso/9780198567882.001.0001

Lillywhite, R. D., C. Keeling, P. Courtney, N. Lampkin, B. Pearce, F. Rayns, M. Reed, U. Schmutz, C. Watson, and A. Williams. 2012. Assessing the economic, environmental and social characteristics of UK farming systems. In Producing and reproducing farming systems: new models of organisation for sustainable food systems of tomorrow. 10th European IFSA symposium. International Farming Systems Association - Europe Group, Vienna, Austria. [online] URL: http://ifsa.boku.ac.at/ cms/fileadmin/Proceeding2012/IFSA2012 WS6.1 Lillywhite.pdf

López-Ridaura, S., O. Masera, and M. Astier. 2002. Evaluating the sustainability of complex socio-environmental systems: the MESMIS Framework. Ecological Indicators 2:135-148. http://dx. doi.org/10.1016/S1470-160X(02)00043-2

Meadows, D. 1998. Indicators and information systems for sustainable development. The Sustainability Institute, Hartland Four Corners, Vermont, USA.

Meul, M., S. Van Passel, F. Nevens, J. Dessein, E. Rogge, A. Mulier, and A. Van Hauwermeiren. 2008. MOTIFS: a monitoring tool for integrated farm sustainability. Agronomy for Sustainable Development 28:321-332. http://dx.doi.org/10.1051/agro:2008001

Migliorini, P. 2013. The sustainability assessment of agro-food systems and diets. The comparison of IFOAM vs Slow Food networks. Pages 74-81 in A. Wezel, E. Rembiałkowska, and C. Francis, editors. Learning in future farming and food systems: European education in organic agriculture and agroecology. Proceedings of ENOAT Workshop, Lyon, 30 August - 1 September 2012. ISARA-Lyon, Lyon, France.

Organisation for Economic Co-operation and Development (OECD). 1999. Environmental indicators for agriculture. Vol. 2. Issues and design. OECD, Paris, France.

Organisation for Economic Co-operation and Development (OECD). 2001. Environmental indicators for agriculture. Vol. 3. Methods and results. OECD, Paris, France.

Pacini, C., G. Lazzerini, P. Migliorini, and C. Vazzana. 2009. An indicator-based framework to evaluate sustainability of farming systems: review of application in Tuscany. Italian Journal of Agronomy 1:23-39.

Peano, C., F. Sottile, V. Girgenti. In press. I Presidi Slow Food in Europa, un modello di sostenibilità. Franco Angeli, Milan, Italy.

Petrini, C. 2005. Buono, pulito e giusto: principi di nuova gastronomia. Einaudi, Torino, Italy.
Pretty, J., and H. Ward. 2001. Social capital and the environment. World Development 29:209-227. http://dx.doi.org/10.1016/ S0305-750X(00)00098-X

Reed, M., E. D. G. Fraser, S. Morse, and A. J. Dougill. 2005. Integrating methods for developing sustainability indicators to facilitate learning and action. Ecology and Society 10(1): r3. [online] URL: http://www.ecologyandsociety.org/vol10/iss1/ resp3/

Romano, D. 1996. Endogenous rural development and sustainability: a European (non orthodox) perspective. Proceedings of the fifth conference on agriculture, food, and the environment, Abano Terme, Padova, Italy. Working Paper WP964, Center for International Food and Agricultural Policy, University of Minnesota, St. Paul. Minnesota, USA. [online] URL: http://ageconsearch.umn.edu/bitstream/14396/1/wp9642b. pdf

Schader, C., J. Grenz, M. S. Meier, and M. Stolze. 2014. Scope and precision of sustainability assessment approaches to food systems. Ecology and Society 19(3): 42. http://dx.doi.org/10.5751/ ES-06866-190342

Schönhart, M., M. Penker, and E. Schmid. 2009. Sustainable local food production and consumption: challenges for implementation and research. Outlook on Agriculture 38(2):175-182. http://dx.doi. org/10.5367/000000009788632313

Segnestam, L., M. Winograd, and A. Farrow. 2000. Developing indicators: lessons learned from Central America. World Bank, UNEP, Washington, D.C., USA.

Shiva, V. 1993. Monocolture della mente. Bollati Boringhieri, Torino, Italy.

Shiva, V. 2009. Ritorno alla terra. Fazi editore, Toma, Italy.

Slow Food Foundation for Biodiversity. 2010. Slow food presidia: handbook. Slow Food Foundation for Biodiversity, Bra (Cn), Italy. [online] URL: http://www.slowfoodfoundation.com/filemanager/ pdf fondazioneslowfood/Vademecum_EN.pdf

Tregear, A. 2001. What is a 'typical local food'? An examination of territorial identity in foods based on development initiatives in the agrifood and rural sectors. Working Paper 58. Centre for Rural Economy, University of Newcastle, Newcastle, UK. [online] URL: http://www.ncl.ac.uk/cre/publish/pdfs/wp58.pdf

Triste, L., F. Marchand, L. Debruyne, M. Meul, and L. Lauwers. 2014. Reflection on the development process of a sustainability assessment tool: learning from a Flemish case. Ecology and Society 19(3): 47. http://dx.doi.org/10.5751/ES-06789-190347

United Nations General Assembly. 1992. Report of the UN Conference on environment and development. A/CONF.151/26/ Rev.1. United Nations, New York, New York, USA. [online] URL: http://www.un.org/documents/ga/conf151/aconf15126-4. $\underline{\mathrm{htm}}$

Van Calker, K. J., P. B. M. Berentsen, G. W. J. Giesen, and R. B. M. Huirne. 2005. Identifying and ranking attributes that determine sustainability in Dutch dairy farming. Agriculture and Human Values 22:53-63. http://dx.doi.org/10.1007/s10460-004-7230-3 
Van Cauwenbergh, N., K. Biala, C. Bielders, V. Brouckaert, L. Franchois, V. Garcia Cidad, M. Hermy, E. Mathijs, B. Muys, J. Reijnders, X. Sauvenier, J. Valckx, M. Vanclooster, B. Van der Veken, E. Wauters, and A. Peeters. 2007. SAFE-A hierarchical framework for assessing the sustainability of agricultural systems. Agriculture, Ecosystems \& Environment 120:229-242 http://dx.doi. org/10.1016/j.agee.2006.09.006

Van Der Ploeg, J. D. 1995. Beyond modernization: the impact of endogenous rural development. Van Gorcum, Assen, The Netherlands.

Van der Werf, H. M. G., and J. Petit. 2002. Evaluation of the environmental impact of agriculture at the farm level: a comparison and analysis of 12 indicator-based methods. Agriculture, Ecosystems \& Environment 93(1-3):131-145. http:// dx.doi.org/10.1016/S0167-8809(01)00354-1

Wilson, E. O. 1992. The diversity of life. Harvard University Press, Cambridge, Massachusetts, USA.

World Commission on Environment and Development. 1987. Report of the World Commission on Environment and Development: our common future. Oxford University Press, Oxford, UK. 